\title{
Remotely Garden Irrigation for Residential Area Based on Internet of Things (IoT)
}

\author{
LITA LIDYAWATI ${ }^{1}$, LISA KRISTIANA ${ }^{2}$, ARSYAD RAMADHAN DARLIS ${ }^{3}$, \\ LUCIA JAMBOLA4, RATNA SUSANA ${ }^{5}$
}

\author{
1,2,3,4,5Institut Teknologi Nasional Bandung
}

Email: lita@itenas.ac.id

\author{
Received 30 May 2020 | Revised 07 June 2020 | Accepted 24 June 2020
}

\begin{abstract}
Activities such as planting and gardening become one of prominent hobbies. An issue of having such well grown plants is the impractical and unachieavable task to monitor 24 hours a day, thus we need a smart gardening system that can monitor the garden on demand. One of the problems in residential gardening systems is how to water the plants while the owner is not at home. Some of people have an adequate knowledge of using IoT to make their life easier. This paper proposes a simple automatic gardening system in watering several plants as programmed. In addition, this system allows human's manual intervention either locally or remotely via Internet, to control a water pump. To build this smart gardening system, we use Xiaomi home application from Google Play. In this application, we can set the program to water the plants daily with definite time periodic independently.
\end{abstract}

Keywords: google play, smart gardening system, time periodic, water pump, Xiaomi

\section{INTRODUCTION}

The thought of making our home a smart home might seem problem for some people. Indeed, when we start cutting into walls and pulling cabling through the void, it might seem like we have lost our senses. Similarly, but at much accelerated pace thanks to computers, we are able to eliminate life's little inconveniences around the home. Home automation is taking a lot of the tedium out of our lives. It is simple enough to flip a switch to turn on everything, a computer can automatically do it for us. From piping audio and video through the home to automatically watering the garden, there are scores of places where smart homes can make our life easier. (Elsenpeter, 2001)

For too long gardeners, farmers, green keepers workers have been locked in a battle with the chore of daily irrigation. Perhaps it is one of the most time-consuming task in agricultural industry and one of the biggest drains of our workforce. The Internet of Things or IoT as we 
call it is the connecting of smart devices together in a network so that they can communicate with each other wirelessly and autonomously. The im of an IoT project is to collect data from smart sensors which are connected to electronic devices.

Several studies have been carried out in the field of remotely irrigation system. In 2020, a study conducted by Gloria (Gloria, 2020) and her team, introduced a new way of managing water in irrigation systems, which can be applied to gardens or agricultural fields, replacing human intervention with wireless sensor network. A typical irrigation system wastes on average $30 \%$ of the water used, due to poor management and configuration. This sustainable irrigation system allows a better efficiency in the process of irrigation that can lead to savings for the end user, not only monetary but also in natural resources, such as water and energy, leading to a more sustainable environment. The system, can retrieve real time data and use them to determinate the correct amount of water to be used in a garden. With this solution, it is possible to save up to $34 \%$ of water when using sensor data from temperature, humidity and soil moisture, or up to $26 \%$ when using only temperature inputs. Besides a detailed system architecture, this paper includes a real case scenario implemantation and results discussion.

In 2018, the research explained by Kamienski (Kamienski, 2018) that the irrigation for agriculture is the biggest consumer of freshwater in the world, which makes a case for the intensive use of technology to optimize the use of water, reduce the consumption of energy and improve the quality of crops. While the Internet of Things (IoT) and other associated technologies are the natural choice for smart water management applications, their appropriateness is still to be proven in real settings with the deployment of on-site pilots. Though, IoT-based application develepoment platforms should be generic enough to be adapted to different crops, climates, and countries. The SWAMP project develops IoT based methods and approaches for smart water management in precision irrigation domain.

In 2019, a discussion delivered by Kamienski (Kamiensi, 2019) was about the smart management of freshwater for precision irrigation in agriculture to increase crop yield and decrease costs, while contribute to environmental sustainability. The intense use of technologies offers a means for providing the exact amount of water needed by plants. The Internet of Things (IoT) is the natural choice for smart water management applications, eventhough the integration of different technologies required for making it work seamlessly in practice is still not fully accomplished. The SWAMP project develops an IoT-based smart water management paltform for precision irrigationin agriculture. This paper presented the SWAMP architecture, paltform, and system developments that hihlight the replicability of the platform, and, as scalability is amajor concern for IoT applications, it includes a performance analysis of FIWARE components used in the platform. Results showe that it is able to provide adequate performance for the SWAMP pilots, but requires specially designed configurations and the reengineering of some components to provide higher scalability using less computational resources.

In 2017, the paper explained by Rajkumar (Rajkumar, 2017) and his team, tried to use IoT as a multidisplinary concept that encompasses a wide range of several technologies, applications domains, device capabilities, and operational strategies, etc. The ongoing IoT reseacrch activities are directed towards the definition and design standards and open architectures which is still have the issues requiring a global consensus before the final deployment. This paper gave over view about IoT technologies and applications related to agriculture with comparison of other survey papers and proposed a novel irrigation management system. The objective of this work is to for farming where various new technologies to yield higher growth of the crops and their water supply. Automated control 
features with latest electronic technology using microcontroller which turns the pumping motor ON and OFF on detecting the dampness content of the earth and GSM phone line is proposed after measuring the temperature, humidity, and soil moisture.

In 2016, a study conducted by Masaba (Masaba, 2016) and his team, explored a smart irrigation system to identify specific areas to irrigate. The system is comprised of microcontroller, sensors, and integration of water pumps with the decision making system. A truth table is developed to help the system determine the necessity to irrigate based on the location that requires irrigation and the decision-making system activates sprinkles. In this fashion, water is given to dry locations in the field, already damp locations are not irrigated and this results efficient water use. Different parameters used, i.e. temperature, humidity, and moisture, makes it possible to adjust the system according to the needs of a particular location.

In 2017, a research delivered by Routray (Routray, 2017), tried to apply millions of sensors that will be deployed for the implementation of IoT related services. Even in the normal cellular architecture, IoT will be deployed as a value added service for several new applications. Such massive deployment of IoT sensors and devices would certainly cost a large sum of money. In addition to the cost of deployment, the running costs or the operational expenditure of the IoT networks will incur huge power bills and spectrum license charges. As IoT is going to be a pervasive technology, its sustainability and environmental effects too are important. Energy efficiency and overall resource optimization would make it the long term technology of the future. Therefore, green IoT is essential for the operators and the long term sustainability of IoT itself. In this article we consider the green initiatives being worked out for IoT. We also show that narrowband IoT as the greener version right now.

In 2018, the paper discussed by Pernapati (Pernapati, 2018), tried to use smart techniques for reducing the percentage of wasting availbale water for the irrigation. We have been seeing the huge demand for the internet of things in every domain from small and simple applications to large and complex applications. Practically implementation of a smart irrigation is very complex deal, but association with IoT using Smart wireless sensors, it brings a great management system. The humidity and temperature sensor sense the both water vapor content and temperature around the plant. The soil moisture sense the soil moisture of a plant, if water content is below minimum requirement then water will supply from water reservoir using relay and ultrasonic sensor measures the water level of reservoir after that sends the data to ESP8266 NodeMCU. The ESP8266 NodeMCU is a microcontroller gets the data from smart wireless sensors, process the data and send to destination through a Message Queue Telemetry Transport (MQTT) protocol.

In 2020, the paper delivered by Ngipol (Ngipol, 2020), concerned about the insufficiency of technology and the use of traditional methods of farming results to low yielding of crops. The integration of smart agriculture using Internet of Things is an absolute solution in modernizing the traditional methods of farming. This paper aims to design and develop an IoT-driven system for high valued crop farming which automates farming processes like watering, distribution and application of fertilizer. It provides real-time monitoring and collection of information about the farm conditions like moisture, temperature, fertility of soil and level of water. Qualitative and quantitative data were gathered by means of interview and survey questionnaires which were given to Alfonso Lista, Ifugao farmers and Yaojiaxi Corporation personnel. The majority of the respondents evaluated the functionality of the system as "Fully Functional", usability as "Very Usable", efficiency as "Mostly Efficient" and maintainability as "Mostly Agree" based from the result of ISO standard criteria survey 
questionnaires. The developed prototype realized smart farming which promotes sustainable agriculture involving the integration of IoT technology into existing farming practices that definitely reduces manual work, man power and provides efficiency on the use of farming resources.

As we are considering all of the studies above, we meet very complex architecture to build. For the ordinary people, who lack of knowledge about IoT, will be very difficult to accomplish those systems.

In this paper, we propose the simple automatic gardening system that can automatically water the garden daily and at specified times. The people can shut the water off in case of flooding or to perform maintenance on a section of the system without needing access to a home, saving time and effort in management and maintenance of a residential property. The application is so as simple as that, thus, the main aim of this paper is to give more knowledge to people who inadequate ability using IoT. We use Xiaomiapplication to centrally manage the devices that can be connected to a single smart-home system. To do this, we just need to install the MiHome application (available for both Android and iOS) and can download the Xiaomi Mi Home from play store (Android Phone), or from APP store (iPhone). In Xiaomi application, we can set the schedule period, schedule on time, and schedule off time in one time. Thus, everyone can build their own irrigation system with easier method.

\section{METHOD}

\subsection{Components}

The primary method we are going to use is to add functionality to our smart garden through many components and a software.

\subsubsection{Xiaomi MiHome}

Before adding a device, we have to install the application via google play. We will start with the home page interface and it shows in Figure 1. The device which is applying in smart gardening must be registered in this application.

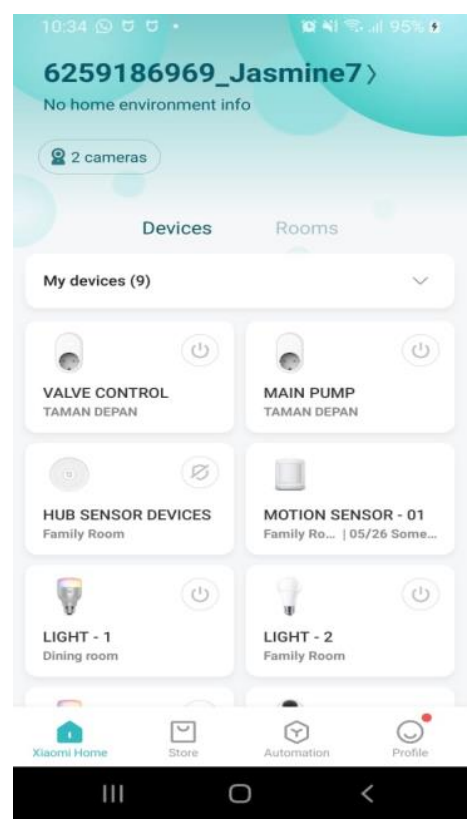




\section{Figure 1. The Xiaomi Home Page}

The application consist of four programs, i.e. xiaomi home to add device and recommendation, store, automation, and profile to set profile photo, name the count, reset the password or exit the account.

\subsubsection{Switch based on IoT}

The smart switch based on IoT allows to control home appliances from anywhere that we can connect to the internet. The switch has to configure for automatic setting. The switch is registered in application via bluetooth media. Figure 2 shows the registered switch in software application.

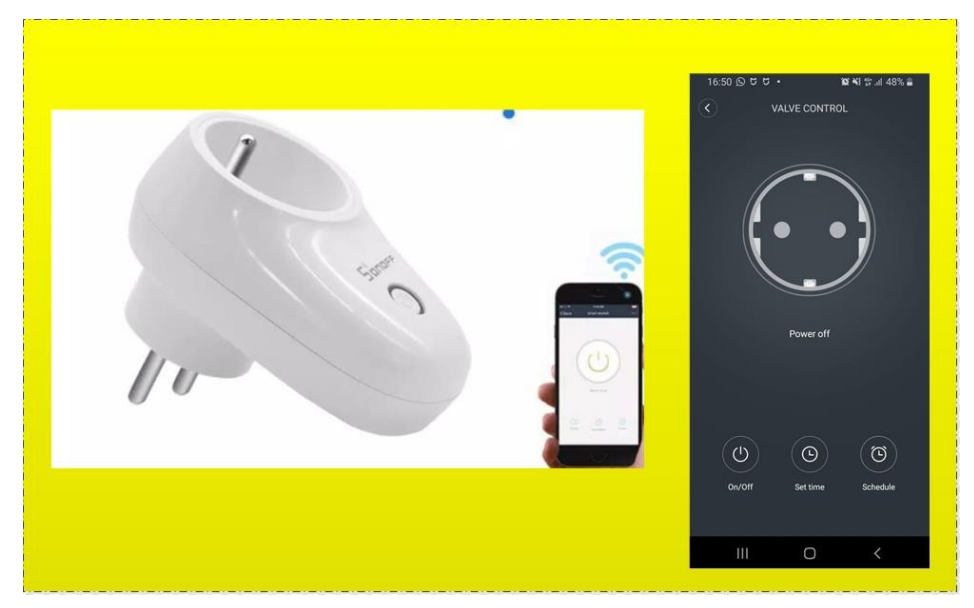

Figure 2. The Switch based on IoT

\subsubsection{The Valve based on IoT}

Traditionally if we want a tap or valve turned on or off we did it by hand which is not an issue when it is on a residential block but a big deal when we have hundreds of valves to control right across a wide area or thousands across a utility network.

In this paper, we use a valve that connected to the smart switch which effortlessly gives the users complete control over the flow. Figure 3 shows the valve based on IoT that is connected to the smart switch.

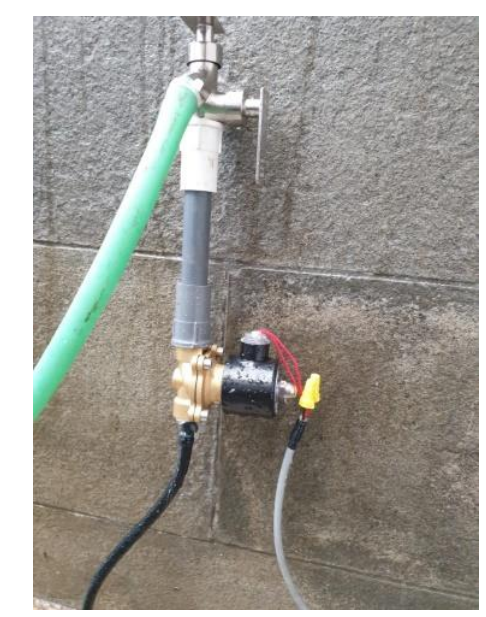

Figure 3. The Valve based on IoT 


\subsubsection{Snip and Drip Soaker}

The snip and drip soaker system uses a soaker hose to provide the slow, deep watering that plants love. By applying water at the root and stem zone, it keeps foliage dry, helping to prevent disease problems and it conserves water as well. Figure 4 shows the snip and drip soaker system applies in the smart gardening.

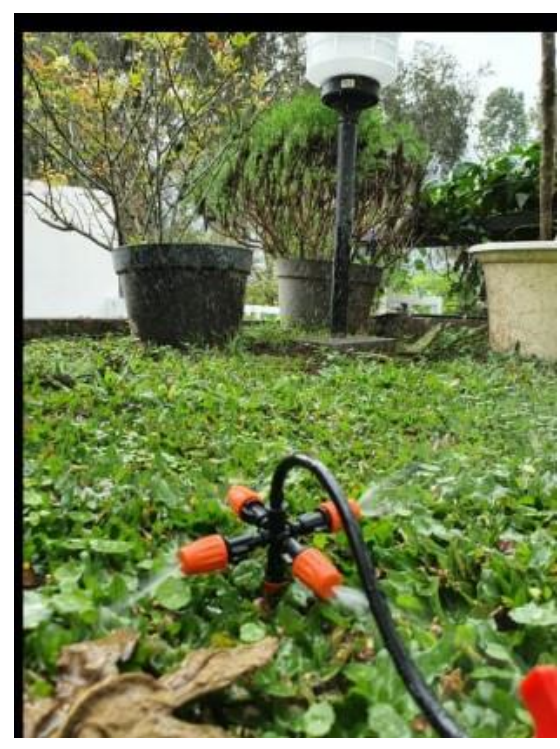

Figure 4. The Snip and Drip

\subsection{IoT irrigation System}

The edge-device includes network technologies such Wi-Fi, Bluetooth and 3G which serves as gateway that provides data routing and addressing paths for network communication. The server and backend includes the mobile application and the monitor that constitute the front end of the whole IoT framework which provides personalized based services according to user relevant needs.

The system diagram of a typical system is shown in Figure 5 . The system deploys wireless sensor network to connect to a network gateway. Due to the high-data transmission bandwidth requirement in this application, the gateway can access the internet wirelessly by the use of technologies, such as 4G LTE mobile communication network, with comparatively low cost. The data transmitted over mobile network will be received by subscribed web services on the cloud. (Zhang, 2018)

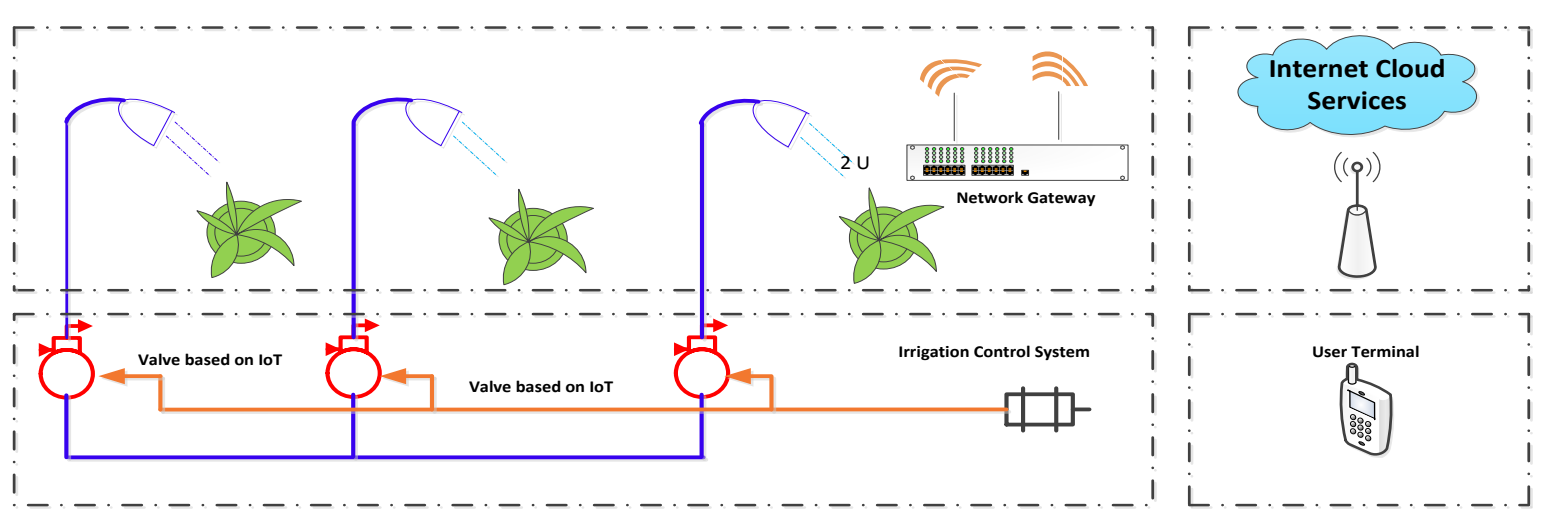

Figure 5. IoT irrigation System Diagram 
The valve based on IoT will be improved operational efficiency of control valve. In a typical processing plant, media or fluids flow through processing equipment. Control valves perform the critical function of regulating process variables, such as pressure and flow rate. All these factors contribute to the overall operational efficiency of the process and the plant.

The primary function of control valves is to regulate the flow of liquids in a process. While the conventional automated control valve systems eliminated the need to switch on or off the valves manually, one still needs to access the main control panel to monitor the valves. With IoT technology, however, plant supervisors can shut down or open valves or change their control parameters remotely.

\section{RESULTS AND DISCUSSION}

Garden irrigation systems offer many significant benefits for homeowners including saving time via automation, efficient watering via direct watering and much more. It is no wonder garden irrigation systems are becoming massively and popular worldwide.

If we are starting our journey in planning and installing a garden irrigation system, everything starts with effective planning. We have to map our garden, measure the property boundaries, paths, flower beds, etc. Part of this process is to understand how many outlets are required. Figure 6 shows the area of the garden irrigation and the size is $24 \mathrm{~m}^{2}$.

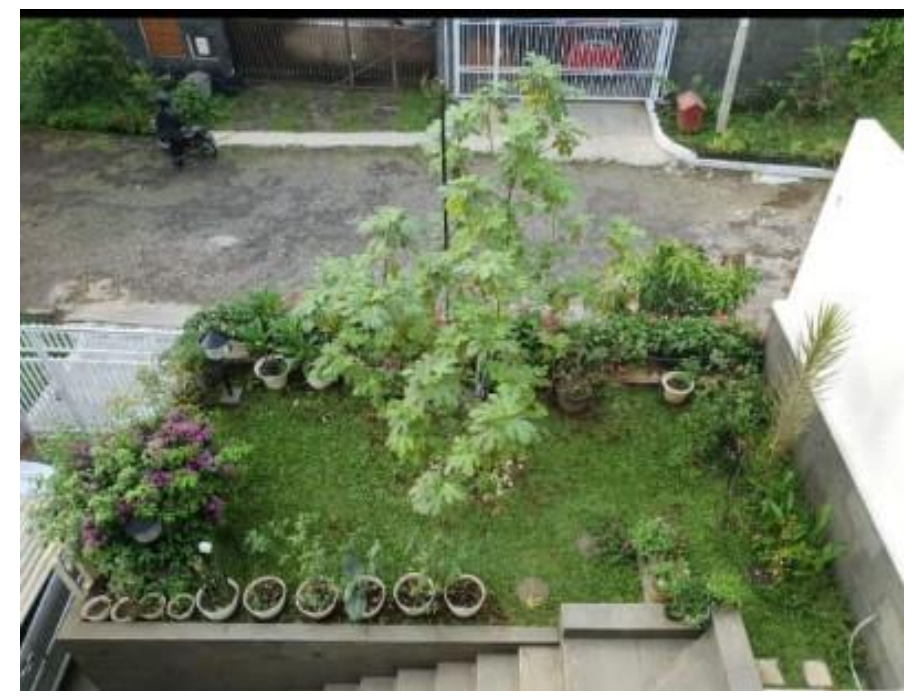

Figure 6. The area of the Garden Irrigation

Drip line irrigation systems work in a similar way as soaker hose, releasing water along its length. Instead of being just a porous pipe, which is unregulated, the drip line is a plastic pipe with pre-determined drip emitters along its length. This makes it much more controlled in the way it releases water as each drip emitter will release a precise amount of water. This precision not only allows for exact watering, but it also allows for much longer runs to be made, in most cases up to $150 \mathrm{~m}$ length. Installation is simple, all that's required is to roll it out in the area to be watered, stake it in place, and connect to a water source. Figure 7 shows the installation of drip line irrigation system in a garden. 


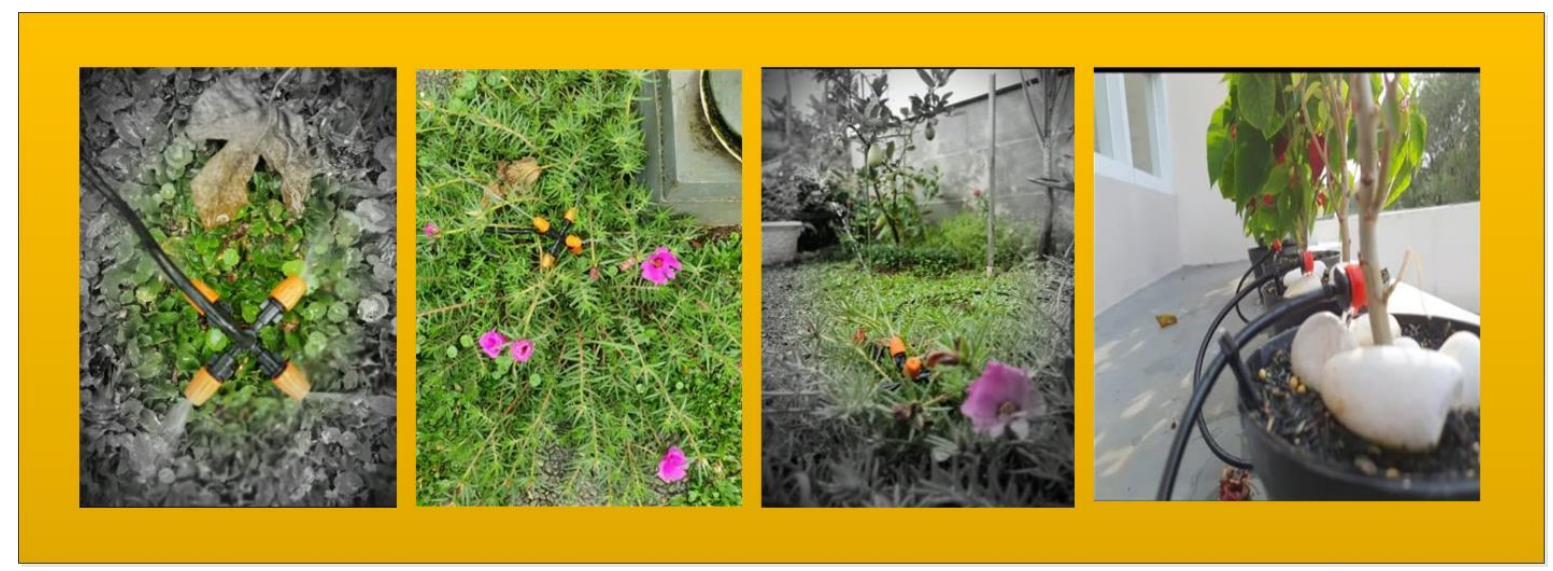

Figure 7. The Installation of Drip Line

After the installation of watering has prepared, hereafter we will flow the water from the smart valve whose the period time can be set. An IoT wireless smart valve which, when fitted to our existing drip network will allow us to controll the flow them over $10 \mathrm{~km}$ away from the convenience a smartphone appication. We schedule for watering daily with twice a day. Table 1 shows the schedule of garden watering system.

Table 1. The Schedule of Garden Watering System

\begin{tabular}{|c|c|c|}
\hline Schedule Period & Schedule On Time & Schedule Off Time \\
\hline Daily & 06.00 & 06.20 \\
\hline Daily & 16.00 & 16.20 \\
\hline
\end{tabular}

Figure 8 shows the smartphone application for managing the schedule of garden watering system.

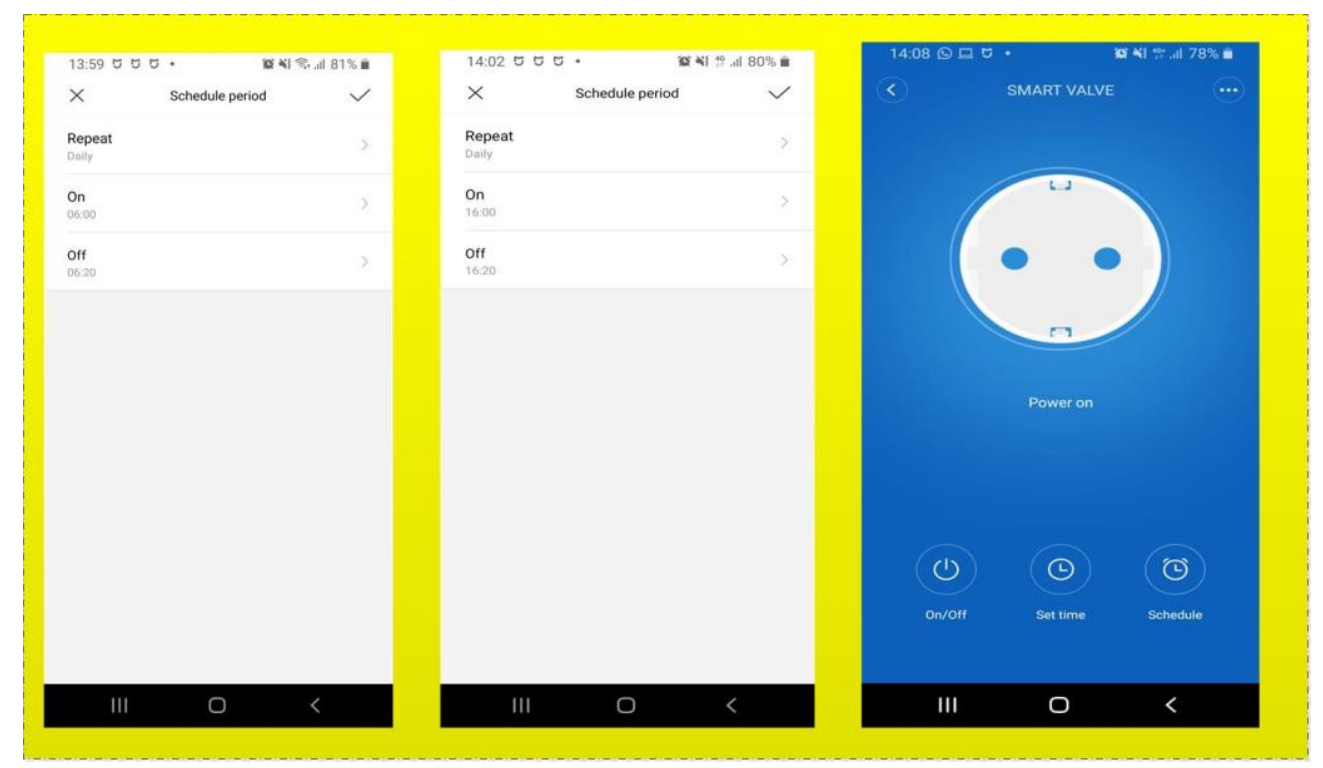

Figure 8. The Smartphone Application for Time Schedulling 


\section{CONCLUSIONS}

The experimental results shows that the IoT can be applied to improve the performance and efficiency of control valves to irrigate the garden remotely and manage the schedule time in anytime.

\section{ACKNOWLEDGEMENT}

This study was supported by Mrs. Liliek Mutiarawati, as the homeowner of Jalan Jasmine No. 7 Bandung.

\section{LIST OF REFERENCES}

Elsenpeter, R.C., Velte, T.J. (2001). Build your Own Smart Home. Osborne: Mc. Graw Hill Gloria, A., Dionisio, C., Simoes, G., Cardoso, J., Sebastiao, P. (2019). Water Management for Sustainable Irrigations Systems using Internet of Things. Proceedings of the 2019 IEEE $5^{\text {th }}$ World Forum on Internet of Things.

Kamienski, C.A., Soinien, J.P., Taumberger, M., Toscano,A., Cinotti, T.S., Dantas, R.A.S., Maia, R.F., Neto, A.T. (2019). Smart Water Management Platform: IoT-Based Precision Irrigation For Agriculture. Sensors, 19, 276.

Kamienski, C., Soininen, J.P., Taamberger, M., Fernandes, S., Toscano, A., Cinotti, T.S., Mai, R.F., Neto, A.T. (2018). SWAMP: an IoT-Based Smart water Management Platform for Precision Irrigation in Agriculture. Proceedings of the 2018 Global Internet of Things Summit (GioTs).

Masaba, K., Ntakirutimana, A., Ustun, T.S. (2016). Design and Implementation of a Smart Irrigation System for Improved Water Energy Efficiency. In Proceedings of the $4^{\text {th }}$ IET Clean Energy and Technology Confrence (CEAT 2016).

Ngipol, D.J.P., Palaong, T.D. (2020). Development of an IoT-Driven System for High Valued Crop Farming. International Journal of innovative Technology and Exploring Engineering (IJITEE). Vol. 9, January 2020.

Pernapati, K. (2018). IoT based Low Cost Smart Irrigation System. In Proceedings of the International Confrenece on Inventive Communication and Computational technologies.

Rajkumar, M.N., Abinaya, S., Kumar, V.V. (2017). Intelligent Irrigation System-an IoT Based Approach. 2017 International Conference on Innovations in Green Energy and Healthcare Technologies (IGEHT). 
Routray, K.S., Sharmila, K.P. (2017). Green Initiatives in IoT. 2017 Third International Confrence on Advances in Electrical, Electronics, Information, Communication and BioInformatics (AEEICB). 27-28 Febuary 2017.

Zhang, L., Dabipi, I.K., Brown Jr., A.L. (2018). Internet of Things A to Z: technologies and Applications. John Wiley \& Sons, Inc. 